\title{
La enseñanza del castellano a vascoparlantes en Argentina: la Gramera berrria, ikasteko eskualdunec mintzatzen espainoles (1850) de Francisco Jáuregui
}

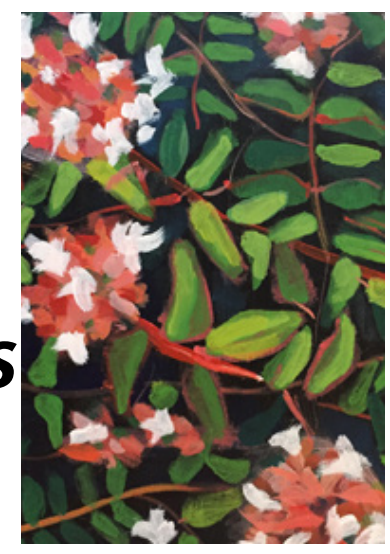

Nerea Fernández de Gobeo Díaz de Durana

Universidad Rey Juan Carlos, España / nerea.gobeo@urjc.es

Trabajo recibido el 24 de abril de 2018 y aprobado el 8 de junio de 2018 .

\begin{abstract}
Resumen
Francisco Jáuregui —o François Jauréguy-, procedente de la localidad vascofrancesa de San Juan de Luz, es autor de Gramera berria, ikasteko eskualdunec mintzatzen espainoles [Nueva gramática, para que los vascos aprendan a hablar en español], publicada en la Imprenta Republicana de Buenos Aires en 1850. La obra es una gramática bilingüe en euskera y castellano, confeccionada con la finalidad de facilitar el aprendizaje del castellano a los vascos que habían emigrado a Argentina y que no dominaban esta lengua. El manual debió de tener cierto éxito, ya que volvió a imprimirse en dos ocasiones -en 1860 y en 1883- en esa misma ciudad. En este trabajo se ha realizado una comparación de dichas ediciones y se ha llevado a cabo una descripción del contenido de la obra, teniendo en cuenta el contexto histórico en el que se inserta su elaboración. Se ha examinado, además, su filiación con otros textos similares.
\end{abstract}

The teaching of Spanish to Basque speakers in Argentina: the Gramera berrria ikasteko eskualdunec mintzatzen espainoles (1850) by Francisco Jáuregui

\footnotetext{
Abstract

Francisco Jáuregui -or François Jauréguy-, from the French town of San Juan de Luz, is the author of Gramera berria, ikasteko eskualdunec mintzatzen espanoles [= New grammar, for Basques to learn to speak in Spanish], published in the Imprenta Republicana of Buenos Aires in 1850. This manual is a bilingual grammar in Basque and Spanish, and it was developed to facilitate the learning of Spanish to the Basque speakers who emigrated to Argentina. The manual had some success, since it was reprinted in 1860 and in 1883, in the same city. In this paper, we have compared these three editions and carried out a detailed description of Jáuregui's text, considering the historical context in which it is inserted. Its affiliation with other similar books has also been examined.
}

\section{Palabras clave}

enseñanza del castellano historiografía lingüística vasco Argentina

Keywords

Spanish language teaching Linguistic Historiography Basque Argentina 


\section{O ensino de espanhol para falantes de basco na Argentina: la Gramera berria ikasteko eskualdunec mintzatzen espainoles (1850) de Francisco Jáuregui}

\begin{abstract}
Resumo
Francisco Jáuregui -o François Jauréguy-, da cidade basca francesa de San Juan de Luz, ele é o autor da Gramera berria, ikasteko eskualdunec mintzatzen espainoles [ = Nova gramática, para que os bascos aprendam a falar em espanhol] publicado na Imprenta Republicana de Buenos Aires em 1850. O trabalho é uma gramática bilíngüe em basco e espanhol, feita com o propósito de facilitar o aprendizado do castelhano aos bascos que emigraram para a Argentina e que não dominavam esta língua. O manual deve ter tido algum sucesso, já que foi reimpresso duas vezes - em 1860 e em 1883 - naquela mesma cidade. Neste trabalho, foi feita uma comparação dessas edições e uma descrição do conteúdo do trabalho foi realizada, levando em consideração o contexto histórico no qual sua elaboração está inserida. Além disso, sua afiliação com outros textos semelhantes foi examinada.
\end{abstract}

\section{Introducción}

La Gramera berria, ikasteko eskualdunec mintzatzen espainoles [Nueva gramática, para que los vascos aprendan a hablar en español] fue elaborada por Francisco Jáuregui (o François Jauréguy), procedente de San Juan de Luz, en el País Vasco francés. El texto, que fue publicado en la Imprenta Republicana de Buenos Aires en 1850, constituye un manual bilingüe en euskera y castellano con el objetivo de facilitar el aprendizaje del castellano a los vascoparlantes que habían emigrado a América y que no dominaban este idioma. La obra está compuesta por unos textos preliminares, unas explicaciones sobre la pronunciación española y vasca, una lista con los numerales cardinales, varias tablas de conjugación verbal, una nomenclatura bilingüe y unas "Frases familiares para la conversación". A pesar de que no contamos con datos sobre su repercusión en la época, el manual debió de tener cierto éxito, ya que se imprimió nuevamente 1860 y 1883 , también en imprentas de la ciudad porteña.

Si bien la Gramera berria ha sido citada y descrita en algunos trabajos (Aramburu 1999, 2001; Auza 2003, 2013; García Aranda 2011a, 2011b; Alvar Ezquerra 2013; Quijada 2015), no ha sido objeto de un análisis pormenorizado, en el que se hayan estudiado las tres ediciones publicadas. Así pues, tras referirnos al contexto histórico en el que se enmarca la publicación de la obra, en este trabajo confrontaremos la estructura y el contenido de las ediciones y describiremos el texto del autor labortano, teniendo en cuenta además su relación con otras obras para la enseñanza de segundas lenguas.

\section{El autor y su contexto: la emigración vasca en Argentina}

Hasta el momento apenas se han podido encontrar datos sobre la vida de Francisco Jáuregui o François Jauréguy, como aparece mencionado en la primera edición. Sabemos únicamente que era originario de San Juan de

\section{Palavras-chave}

ensino de castelhano historiografia linguística basco Argentina 
Luz, localidad perteneciente al País Vasco francés, por la indicación que se incluye en la portada de la obra y por el hecho de que la parte vasca de la obra esté escrita en el dialecto labortano del euskera ${ }^{1}$ (Gómez López 2014). Si tenemos en cuenta el objetivo principal, podemos inferir que la gramática de Jáuregui estaba destinada a los emigrantes vascos que no conocían o no dominaban el castellano y, principalmente, a los procedentes de las provincias del País Vasco francés, como el propio autor (Aramburu 1999, 2001).

La emigración atlántica es un proceso coincidente con otros países europeos durante la centuria decimonónica, pero, según Irianni, se debe "resaltar el carácter temprano de las salidas desde ambas vertientes de los Pirineos" $(2010,31)$. Así, especialmente a partir del segundo tercio del siglo XIX, se verifica un flujo constante de emigración vasca a América. Como indica Álvarez Gila, en contraposición con los movimientos migratorios realizados en periodos anteriores -en los que van a participar los vascos procedentes de la Península-, a partir de ese momento "también se incorporaban al proceso, con gran fuerza, los vascos continentales, quienes por su condición política de franceses habían tenido vedado el acceso oficial a las colonias americanas de España durante los siglos anteriores" (Álvarez Gila 2002, 460). Por otro lado, a pesar de que fueron varios los países a los que arribaron los emigrantes procedentes de las regiones vascas, "a lo largo del siglo XIX y buena parte del XX, el Río de la Plata fue una de las principales regiones de América receptoras de la emigración ultramarina vasca”2.

En esta fase temprana de flujo migratorio, los primeros inmigrantes vascos en instalarse en Argentina fueron los oriundos de Iparralde - es decir, de la parte francesa- $y$, en especial, los provenientes de las regiones situadas en la costa (Aramburu 2001, 58; Álvarez Gila 2002, 469). A este respecto, si tenemos en cuenta la situación lingüística de los territorios vascos - tanto continentales como peninsulares- en las primeras décadas del siglo XIX, se puede inferir que un número importante de los llegados a Argentina en esa época serían vascoparlantes y que, debido a sus diversos orígenes, se expresarían en los diferentes dialectos del euskera ${ }^{3}$. Como muestra de ello, Aramburu - al igual que otros investigadores ${ }^{4}$ - examina diversos testimonios sobre el uso del euskera en Argentina, que incluimos como ejemplo:

Una referencia que documenta esta situación es la que da Eduardo de Zaballa, quien cita un libro titulado El beato Miguel de Garicoits, en el que se dice que los padres bayoneses "en Buenos Aires cada domingo predicaban en francés y en vascuence" y que "acá tenemos multitud de vasquitos que hablan todos el idioma de su país".

Existe también un documento de la época rosista donde se verifica que en una pulpería se hallaba un señor Espil, hablando "vascuence con otros vascos...". Costumbre que no perdieron hasta el último tercio del siglo XIX, cuando no era infrecuente verlos en las típicas "fondas de vascos" jugando al mus y expresándose en su lengua (Aramburu 2001, 58).

\section{La Gramera berria, ikasteko eskualdunec mintzatzen espainoles}

\subsection{Ediciones}

Como se ha señalado en el apartado introductorio, en este trabajo se han consultado las tres ediciones que se conocen de la obra de Jáuregui (Auza 2013; Esparza y Niederehe 2012, 2015), cuyos datos se detallan a continuación:
1 Como se verá más adelante, en el repertorio léxico incluye, además, diversas notas sobre las variantes en el dialecto bajonavarro del euskera.

En cuanto al desplazamiento hacia el Río de la Plata, desde la segunda década del siglo XIX hasta la mitad de la centuria, la emigración vasca y la europea en general se decantó principalmente por el territorio situado en la actual parte uruguaya. Más adelante, sin embargo, el flujo migratorio se fue inclinando por la vertiente argentina (Álvarez Gila 2002, 462).

3 A pesar de que durante el siglo XIX el euskera sufrirá una importante regresión en los territorios situados en ambas vertientes de los Pirineos, a comienzos de dicho siglo el uso del euskera era mayoritario en gran parte del País Vasco francés, en Guipúzcoa y en áreas de Vizcaya sobre todo en las zonas rurales, frente a una presencia mucho más limitada en las provincias del interior de la Península como Álava y Navarra (Fernández de Gobeo 2017, §5).

4 Entre ellos, Álvarez Gila $(2002,466)$ se hace eco también de diversas declaraciones sobre la relevante presencia de la lengua vasca en el Buenos Aires de mitad del siglo XIX y de testimonios de su uso en la ciudad porteña.

5 Este testimonio hace referencia a la presencia, a partir de 1852 , de religiosos de la Sociedad de Sacerdotes del Sagrado Corazón de Jesús de Betharram fundada por el sacerdote bayonés Miguel Garicoits (1797-1863) y que eran conocidos en Argentina y Uruguay como los padres bayoneses o padres vascos. Estos religiosos abrieron una iglesia en Buenos Aires y en

Montevideo, y en 1858 fundaron un colegio en la ciudad de Buenos Aires, el colegio de San José (Álvarez Gila 2009, 11). 
1850 Gramera berria ikasteko eskualdunec mintzatzen espainoles, dibiditua bi partetan; lehena ortografiaren gainian, eta bigarrena lenguayaren ikasteko erreski mintzatzen. Buenos Aires: Imprenta Republicana ${ }^{6}$.

1860Gramera berria ikasteko eskualdunec mintzatzen espainoles; o sea Nueva gramática para enseñar a los vascos a hablar español. Buenos Aires: Librería de Pablo Morta?.

1883 Gramera berria ikasteko eskualdunec mintzatzen espainoles; o sea Nueva gramática para enseñar a los bascos a hablar español. Buenos Aires: Igon Hermanos ${ }^{8}$.

Las diferencias en cuanto al contenido en las tres ediciones son muy escasas, como se puede apreciar en la tabla que presentamos seguidamente:
6 Hemos consultado los ejemplares sitos en la Biblioteca Nacional Mariano Moreno de Buenos Aires, con las signaturas TES3A064242 y S2BG232307U. 7 Biblioteca Nacional Mariano Moreno, Buenos Aires, S2BG232105P; Oxford University, Bodleian Library, 3109 e.34. El ejemplar de la Universidad de Oxford está digitalizado y se puede consultar a través de la Biblioteca

Virtual de la Filología Española: https://bvfe.es/directorio-bibliograficode-gramaticas-tratados-gramaticaleshistoria-de-la-lengua/12176-grameraberria-ikasteko-eskualdunec-mintzatzen-espainoles-dibiditua-bi-partetano-sea-nueva-gramatica-para-ensenara-los-vascos-a-hablar-espanol.html [última consulta: 22/02/2018].

\begin{tabular}{|l|l|l|}
\hline 1850 & 1860 & 1883 \\
\hline & Introducción: III-XVI & Introducción: III-XVI \\
\hline Autorraren prefaziua9: 3-4 & Autorraren prefaziua: 3-4 & Autorraren prefaziua: 1-2 \\
\hline Abisa $^{10}: 5-12$ & Abisa: 5-12 & Abisa: 3-9 \\
\hline Lección Primera: 13-29 $^{\text {Lección Primera: } 13-29}$ & Lección primera: 10-26 \\
\hline Lehen liburua ${ }^{11}:$ 30-92 & Lehen liburua: 30-92 & Lehen liburua: 27-93 \\
\hline $\begin{array}{l}\text { Frases familiares para la conversación: } \\
\text { 92-120 }\end{array}$ & $\begin{array}{l}\text { Frases familiares para la conversación: } \\
92-120\end{array}$ & $\begin{array}{l}\text { Frases familiares para la conversación: } \\
\text { 93-124 }\end{array}$ \\
\hline
\end{tabular}

Tabla 1: Diferencias entre las ediciones de la Gramera berria.

Se observa que el cambio más significativo es la incorporación de un apartado introductorio al comienzo de la segunda edición de la gramática. Como se puede ver, la adición de esta introducción no afecta a la paginación de la obra, ya que la sección se pagina con números romanos de forma independiente. Por otro lado, hemos podido constatar la similitud entre la primera y la segunda ediciones, exceptuando la mencionada introducción que se inserta en la segunda: la estructura y el contenido de la obra son los mismos, así como la disposición del texto a lo largo de la obra, y la paginación coincide en todos los casos. Solo hemos advertido en la segunda edición algún cambio mínimo, principalmente derivado de la corrección de algunas de las erratas que se hallaban en la primera.

\subsection{Estructura y contenido}

Como se ha indicado más arriba, la Gramera berria de Jáuregui está formada por un prólogo escrito por Juan Mariano Larsen -en las ediciones segunda y tercera-, un prefacio y una advertencia escritos por el autor, unas listas con los numerales ordinales y cardinales, un apartado de conjugación verbal, un repertorio léxico y unas frases usuales y refranes en euskera y castellano.

\subsubsection{Textos preliminares}

El primer texto que se incluye en la segunda edición y que aparece también en la tercera es una introducción escrita por Juan Mariano Larsen
8 Se han consultado los ejemplares de la Biblioteca Nacional Mariano Moreno, Buenos Aires, S2BG192510P; la Biblioteca Koldo Mitxelena, San Sebastián, J.U. 3280; y la Bibliothèque nationale de France, París, Z BASQUE-334. El ejemplar de la Biblioteca Koldo Mitxelena está digitalizado y disponible en internet: (http:// www.kmliburutegia.net/Record/14753), así como el de la Bibliothèque Nationale de France: http://gallica.bnf. fr/ark:/12148/bpt6k97643844.

9 Prefacio del autor [la traducción es mía].

10 Advertencia [la traducción es mía]. 11 Primer libro [la traducción es mía]. 
(1821-1894), de origen francés pero residente en Argentina desde la infancia y, como se afirma en la portada de la propia gramática, "miembro del Instituto Histórico y profesor en la Universidad”.

En este apartado, Larsen examina las ideas sobre la llegada de los vascos al continente americano antes de Colón y sobre la antigüedad de la lengua vasca —según él, "un punto sobre el cual no hay duda es la originalidad y antigüedad del vasco, antigüedad tal que ninguna lengua puede blazonar [sic] de otra mayor" $(1860, \mathrm{~V})$ - Menciona también las diversas teorías sobre su origen, desarrolladas por diversos estudiosos y vascólogos, tanto coetáneos como anteriores $^{12}$. Junto con esto, explica la sola aparición de nombres (sustantivos y adjetivos) y verbos en la gramática de Jáuregui y expone ciertas características del euskera para el lector que no conoce esta lengua ${ }^{13}$. Al final de esta introducción, Larsen incluye parte de un texto del escritor guipuzcoano José María Goizueta (1820-1884), en el que se recogen tres cantares míticos junto con los comentarios de alabanza al pueblo vasco realizados por este escritor: el "canto del soldado de Annibal" (pp. XI-XIII), el "canto de Lecobide" (p. XIII) y el "canto de Altabizcar" (pp. XIII-XIV). Según hemos podido comprobar, parece que Larsen adapta el texto de Goizueta que fue publicado en la revista quincenal La América: crónica hispano-americana el 24 de junio de 1859.

Tras la introducción de Larsen, se incluye el prefacio del autor ("Autorraren prefaziua"), en euskera. En él, Jáuregui habla sobre la necesidad de elaborar una obra de este tipo para los vascoparlantes y ofrece ciertas explicaciones sobre la diferencia en la pronunciación entre el castellano y el euskera.

Después del prefacio, Jáuregui inserta una advertencia ("Abisa”) en la que presenta el abecedario castellano y explica el uso de la tilde en español. Habla también sobre el género gramatical — que no se distingue en euskera-, explicando cuándo debe incluirse el artículo masculino y el femenino, tanto en plural como en singular. Indica asimismo las terminaciones más habituales en ambos géneros y algunas de las excepciones. Después de una aclaración sobre el origen del euskera —en euskera y en castellano-, en la que cita a Estrabón, el autor incluye unas explicaciones sobre la pronunciación, nuevamente tanto en castellano como en euskera.

Más adelante, introduce una serie de palabras vascas similares a voces latinas, y cita de nuevo a Manuel de Larramendi o al abad e historiador de Hasparren —en el País Vasco francés- Pierre Diharce de Bidassouet (1765-1843) (Jáuregui 1850, 12):

Una porción de palabras Vascongadas, encontrarán los lectores, semejante al latín, a pesar de que el Sr. Larramendy y Diharce, sostienen que la Cantabria jamás ha recibido palabras de otros idiomas, antes bien, los Romanos han tomado de la Cantabria, vg.

\begin{tabular}{|l|l|}
\hline BASCONGADO. & LATÍN. \\
\hline $\begin{array}{l}\text { Bekatua azectatzia. } \\
\text { Afligitzia akusatzia. }\end{array}$ & $\begin{array}{l}\text { Pecatum aceptare. } \\
\text { Afligere acusare. }\end{array}$ \\
\hline
\end{tabular}

\subsubsection{Lección primera}

Jáuregui comienza la "Lección primera” presentando los numerales cardinales y ordinales situados de forma contrastiva, primero en euskera y
12 Así, Larsen menciona, entre otros, a Manuel de Larramendi (1690-1766), Pablo Pedro de Astarloa (1752-1806), Juan Bautista Erro (1773-1835) o Wilhelm von Humboldt (1767-1835). Las ideas en torno a la lengua vasca de buena parte de los autores mencionados por Larsen se recogen en la obra de Madariaga (2008).

13 Larsen habla sobre el nombre y el verbo en su explicación: El verbo incorpora en sus afijos y desinencias el régimen directo y el indirecto; lo que le da "una variedad asombrosa. El nombre por su parte tiene una multitud de casos, y sobre estas dos circunstancias se fundan las analogías que se le han encontrado con el Sánscrito [...] Todo lo que en otras lenguas son partículas, adverbios, preposiciones y conjunciones, no son en vasco más que nombre en caso determinado. La construcción es inversa, como en otras lenguas en que la desinencia da el sentido, y por lo demás hay libertad en la disposición de la frase. Con esta corta ojeada no se sorprenderá el lector que no es vasco al recorrer esta gramática en que no figuran más que nombres y verbos. $A$ la verdad es cosa tan estraña que bien merecía una palabra de explicación" (Larsen 1860, VIII-IX). 
después en castellano. Tras los numerales, inserta un apartado con las conjugaciones de varios verbos: tener, ser, amar, temer y partir ${ }^{14}$. El autor no da explicaciones sobre las conjugaciones, sino que se limita a incluir en dos columnas - la primera en euskera y la segunda en castellano- las diferentes formas. Jáuregui diferencia entre indicativo, imperativo y subjuntivo, y no incluye referencias sobre el infinitivo. Salvo en el caso de amar, en cuyo apartado no incluye algunos tiempos verbales, el paradigma verbal que presenta Jáuregui es el siguiente:
14 Son los ejemplos que aparecen en la Gramática de la Real Academia publicada en 1796.

\begin{tabular}{|c|c|c|}
\hline Indicativo & Imperativo & Subjuntivo \\
\hline $\begin{array}{l}\text { Indicativo presente } \\
\text { Ni naiz } \\
\text { Yo soy }\end{array}$ & \multirow{8}{*}{$\begin{array}{l}\text { Izan hadi } \\
\text { Sé tú }\end{array}$} & $\begin{array}{l}\text { Presente } \\
\text { Ni naizela } \\
\text { Yo sea }\end{array}$ \\
\hline $\begin{array}{l}\text { Imperfecto } \\
\text { Ni nintzen } \\
\text { Yo era }\end{array}$ & & $\begin{array}{l}\text { Imperfecto } \\
\text { Ni izan nindadin } \\
\text { Yo fuese }\end{array}$ \\
\hline $\begin{array}{l}\text { Pretérito definido } \\
\text { Ni nintzela } \\
\text { Yo fui }\end{array}$ & & \multirow{3}{*}{$\begin{array}{l}\text { Pretérito } \\
\text { Ni izanic } \\
\text { Yo haya sido }\end{array}$} \\
\hline $\begin{array}{l}\text { Pretérito indefinido } \\
\text { Ni izan naiz } \\
\text { Yo he sido }\end{array}$ & & \\
\hline $\begin{array}{l}\text { Pretérito anterior } \\
\text { Ni izan banintzen } \\
\text { Yo hube sido }\end{array}$ & & \\
\hline $\begin{array}{l}\text { Plus cuam perfecto } \\
\text { Ni nintzela } \\
\text { Yo había sido }\end{array}$ & & $\begin{array}{l}\text { Plus cuam perfecto } \\
\text { Ni izanen nintzen } \\
\text { Yo hubiese sido }\end{array}$ \\
\hline $\begin{array}{l}\text { Futuro } \\
\text { Ni izanen naiz } \\
\text { Yo seré }\end{array}$ & & $\begin{array}{l}\text { Futuro } \\
\text { Ni banintz } \\
\text { Yo fuere }\end{array}$ \\
\hline $\begin{array}{l}\text { Futuro compuesto } \\
\text { Ni izan naitake } \\
\text { Yo habré sido }\end{array}$ & & $\begin{array}{l}\text { Futuro compuesto } \\
\text { Ni izan nintake } \\
\text { Yo hubiere sido }\end{array}$ \\
\hline
\end{tabular}

Tabla 2: Paradigma verbal presentado por Jáuregui.

Si bien los ejemplos no coinciden, el paradigma verbal presentado por Jáuregui es muy parecido al que se incluye en el Arte de hablar bien francés (1781) del maestro de lenguas francés Pierre-Nicolas Chantreau (1741$1808)^{15}$, del que hablaremos en el epígrafe siguiente. No obstante, Jáuregui no introduce las formas del condicional presente y el condicional pasado que sí encontramos en el Arte de este maestro francés, y tampoco las formas del infinitivo.

\subsubsection{Lehen liburua}

15 El paradigma verbal difiere del que nos encontramos en la tradición gramatical académica, por ejemplo (RAE 1796). En este sentido, si observamos la tabla anterior, vemos que Jáuregui diferencia dentro del pretérito, la forma fui como definido, yo he sido como indefinido, y yo hube sido como pretérito anterior.

En la página 30 comienza el primer libro ("Lehen Liburua"), en el que se incluyen las voces más usuales para comenzar a aprender español. El repertorio léxico se distribuye en dos columnas - la primera en euskera y la segunda en castellano- y se divide en adjetivos, verbos y sustantivos. Como indica García Aranda (2011b), los adjetivos se encuentran, en general, por pares de antónimos, y los verbos y sustantivos están ordenados temáticamente. El repertorio constituye, por tanto, una nomenclatura. 
Como ya han señalado García Aranda (2011a, 2011b) y Alvar Ezquerra (2013), Jáuregui se basa en el contenido de la nomenclatura incluida en el mencionado Arte de hablar bien francés de Chantreau para elaborar su repertorio. Esto no es nuevo dentro de la tradición de nomenclaturas vasco-románicas, pues es similar a lo realizado por el maestro guipuzcoano Luis de Astigarraga y Ugarte (1767-1840) en el repertorio vasco-castellano que se inserta en el Diccionario manual bascongado y castellano impreso en 1825 en San Sebastián. La nomenclatura de Astigarraga, no obstante, es mucho más corta: si contamos las entradas de las diferentes clases de palabras, obtenemos 1.091 voces $^{16}$ (Fernández de Gobeo 2017, 152-154), en comparación con las 1.819 que hemos computado en el vocabulario de Jáuregui (tabla 3). El número de voces de ambos repertorios, no obstante, queda lejos de las 3.334 que se incluyen en la nomenclatura del maestro francés (Alvar Ezquerra 2013, 365).

Si atendemos a los epígrafes presentados por Jáuregui en la primera edición, que incluimos en la tabla siguiente, se puede observar que estos coinciden en general con los incluidos en el Arte de Pierre-Nicolas Chantreau (Alvar Ezquerra 2013, 362-365), exceptuando algunos de ellos, que se eliminan en el texto estudiado.

\begin{tabular}{|c|c|}
\hline Epígrafes & Entradas \\
\hline Lehen kapitulua. Hitz ajetibo guehienic usatzen direna[c $]^{17}$ & 85 \\
\hline \multicolumn{2}{|l|}{ Bigarren Kapitulua. Berbo usualenac ${ }^{18}$} \\
\hline Del estudio & 31 \\
\hline Del hablar & 26 \\
\hline Del comer y beber & 26 \\
\hline Acciones de la vida & 15 \\
\hline Del vestir & 17 \\
\hline El irse a acostar & 11 \\
\hline Acciones naturales al hombre & 27 \\
\hline Acciones de amor y de odio & 47 \\
\hline Acciones de la memoria y de la imaginación & 51 \\
\hline Acciones de diversión y juego & 19 \\
\hline Ejercicios & 6 \\
\hline Enfermedades y asistencias & 16 \\
\hline Acciones de movimiento & 49 \\
\hline Obras de mano & 96 \\
\hline Para la compra y venta & 44 \\
\hline [Acciones que tocan al culto divino] & 22 \\
\hline Del tiempo & 17 \\
\hline De la vivienda & 10 \\
\hline Castigos y suplicios & 15 \\
\hline Acciones militares & 74 \\
\hline \multicolumn{2}{|l|}{$\begin{array}{l}\text { Hiru garren Kapitulua }{ }^{19} \text {. Susistentziako izen usualenac. Nombres sustantivos más } \\
\text { usuales }\end{array}$} \\
\hline$[\text { De Dios, etc. }]^{20}$ & 29 \\
\hline Los elementos & 5 \\
\hline Los astros & 27 \\
\hline Del tiempo & 27 \\
\hline Días de la semana & 7 \\
\hline Meses del año & 12 \\
\hline Estaciones y fiestas del año & 25 \\
\hline
\end{tabular}

16 García Aranda solamente cuenta los sustantivos, adjetivos y verbos de la nomenclatura de Astigarraga, por lo que señala casi seiscientas veinte voces. Alvar Ezquerra (2013, 460-462), sin embargo, incluye el resto de voces que se insertan en los epígrafes correspondientes al resto de clases de palabras; así, cuenta 1.086 entradas.

17 Primer capítulo. Adjetivos más usados [la traducción es mía].

18 Segundo capítulo. Verbos más habituales [la traducción es mía].

19 Tercer capítulo [la traducción es mía]

20 Los epígrafes entre corchetes son los pertenecientes a la nomenclatura incluida en el Arte (1781) de Pierre Nicolas Chantreau y que faltan en el repertorio de láuregui. 


\begin{tabular}{|c|c|}
\hline Epígrafes & Entradas \\
\hline Individuos del género humano y sus edades & 17 \\
\hline Partes del cuerpo humano & 89 \\
\hline Cosas pertenecientes al cuerpo & 10 \\
\hline Acciones naturales & 9 \\
\hline Los cinco sentidos \&c. & 10 \\
\hline Defectos y enfermedades del cuerpo & 48 \\
\hline Del alma \&c. & 46 \\
\hline Vestidos para hombres & 44 \\
\hline Para las mugeres ${ }^{21}$ & 14 \\
\hline La mesa con comida & 102 \\
\hline El parentesco & 60 \\
\hline Dignidades & 28 \\
\hline Oficiales de justicia & 21 \\
\hline De la iglesia & 52 \\
\hline Dignidades eclesiásticas & 22 \\
\hline Ciencias y artes & 53 \\
\hline Diferentes oficios & 50 \\
\hline Las herramientas & 18 \\
\hline Reinos y estados & 42 \\
\hline Nombres de las naciones & 31 \\
\hline Ciudades principales & 20 \\
\hline Varias religiones y sectas & 10 \\
\hline De una ciudad & 34 \\
\hline De un corral de comedias & 7 \\
\hline De una casa y sus partes & 47 \\
\hline Los muebles de una casa & 38 \\
\hline Batería de cocina & 17 \\
\hline De la escuela & 42 \\
\hline Empleos de una casa ${ }^{22}$ & 16 \\
\hline Nombres de pila más usuales & 41 \\
\hline De los animales & 60 \\
\hline Cosas pertenecientes a las bestias ${ }^{23}$ & 45 \\
\hline Insectos & 23 \\
\hline De algunos pescados \&c. & 19 \\
\hline Metales y minerales & 20 \\
\hline Gomas y perfumes & 7 \\
\hline Del campo y agricultura & 73 \\
\hline Verduras y legumbres & 24 \\
\hline Flores & 12 \\
\hline Diferentes frutas \&c. & 22 \\
\hline Árboles y arbolillos ${ }^{24}$ & 15 \\
\hline Del agua, del mar y navíos & 39 \\
\hline Viage y camino & 8 \\
\hline El caballo con sus jaeces & 12 \\
\hline Pesos y medidas & 11 \\
\hline Líneas de extensión ${ }^{25}$ & 7 \\
\hline Monedas & 16 \\
\hline Diversiones y juegos & 29 \\
\hline Ejercicios & 8 \\
\hline
\end{tabular}

21 Falta el epígrafe "Paños y telas" de Chantreau.

22 En Chantreau "Criados \&c.".

23 No hay voces que pertenecen a ese epígrafe. Este apartado debería titularse "De las aves", siguiendo la nomenclatura de Chantreau.

24 Falta el epígrafe "Cosas pertenecientes a la fruta" que se encuentra en el repertorio de Chantreau.

${ }_{25}$ En Chantreau, "Medidas de extensión". 


\begin{tabular}{|l|c|}
\hline Epígrafes & Entradas \\
\hline Instrumentos de música & 12 \\
\hline Términos militares & 67 \\
\hline De las armas & 23 \\
\hline La fortificación & 9 \\
\hline Virtudes y vicios & 68 \\
\hline Personas viciosas & 20 \\
\hline Total & 1.819 \\
\hline
\end{tabular}

Tabla 3: Epígrafes de la nomenclatura de Gramera berria.

En el ejemplo que sigue se aprecia la similitud entre las dos obras. Como se puede observar, Jáuregui se limita a resumir la nomenclatura, cambiar la parte francesa por la vasca y alterar el orden de las lenguas. En algunos casos se realizan también ligeras modificaciones y adiciones:

\begin{tabular}{|c|c|c|c|}
\hline \multicolumn{2}{|l|}{ Chantreau $(1781,35)$} & \multicolumn{2}{|l|}{ Jáuregui $(1850,73)$} \\
\hline BATERÍA DE COCINA. & BATERÍA DE CUISINE & KOZINAKO ERREMENTAC & BATERÍA DE COCINA \\
\hline Un caldero & un chaudron. & Bertz bat & Un caldero \\
\hline Una caldera & une chaudiére. & Kafetera bat & Una caldera \\
\hline Un puchero & un pot. & Eltzokaria & Un puchero \\
\hline Una olla & une marmite. & Tupina bat & Una olla \\
\hline Una cobertera & un convercle. & Estalgui bat & Una cobertera \\
\hline La espumadera & l'écumoire. & Arrampo kentzeko bat & Una espumadera \\
\hline Un cucharón & une cuillèr à pot. & Zalhu bat & Un cucharón \\
\hline Una tortera & une tourtière. & & \\
\hline Una cacerola & une casserole. & Kazola bat & Una cacerola \\
\hline Una sartén & une paêle. & Zartain bat & Una sartén \\
\hline Las parrillas & le gril. & Grilhac & Las parrillas \\
\hline$[\ldots]$ & {$[\ldots]$} & {$[\ldots]$} & {$[\ldots]$} \\
\hline Una escoba & un balal. & Yatz bat & Una escoba \\
\hline Una rodilla & un torchon. & Tortchoin bat & Una rodilla \\
\hline Los cepillos para los zapatos & les décrotoires. & & \\
\hline DE LA ESCUELA. & DE L’ECOLE & ESKOLAZ. & DE LA ESCUELA. \\
\hline La escuela & l'école. & Eskola & La escuela \\
\hline El estudio & l'étude. & Yztudiyua & El estudio \\
\hline La cáthedra & une chaire. & Errient baten predika teya & La cátedra \\
\hline La aula & l'école, la classe. & Klaza & El aula \\
\hline El Cathedrático & le Professeur. & Profesorra & El catedrático \\
\hline Papel & du papier. & Papera & El papel \\
\hline Papel blanco & du papier blanc. & Paper churia & Papel blanco \\
\hline Papel de estraza & du papier gris. & Paper grisa & Papel de estraza \\
\hline
\end{tabular}

Tabla 4: Similitud entre las nomenclaturas de Chantreau y Jáuregui. 
La nomenclatura de Jáuregui manifiesta características similares a las que nos encontramos en otros repertorios temáticos, como la asistematicidad en la presentación de las voces: entradas con y sin artículo (definido o indefinido), predominio de entradas simples pero también aparición de entradas compuestas, y errores o disonancias en la ordenación de los materiales. Como señala García Aranda, también hay voces que se repiten: "tupina - olla se encuentra tanto en 'La mesa con comida' como en 'Batería de cocina', y behia - la vaca y chahala - ternera en 'La mesa con comida' y 'De los animales'” (García Aranda 2011b, 206). Además, algunas de las voces se encuentran incluidas dentro de epígrafes que no serían los habituales:

\begin{abstract}
Al pastelero al carretero y al bordador hay que buscarlos en "Diferentes oficios" y al jardinero, al tesorero o al secretario en "Empleos de una casa" [...] Ello se debe a que la ordenación y el reparto de voces en capítulos temáticos son subjetivos: el repertorio está ordenado a partir de los criterios establecidos por el autor y las búsquedas son realizadas por lectores que no siempre coinciden con el lexicógrafo en su manera de ordenar y disponer el mundo (García Aranda 2011b, 206).
\end{abstract}

Se incluyen también numerosas advertencias y notas a pie, para ofrecer explicaciones en euskera sobre el significado de la voz o con la variante vasca en otro dialecto. A este respecto, abundan las notas haciendo referencia a la variante en el dialecto bajonavarro. Vemos un ejemplo de todo ello en los siguientes fragmentos de la nomenclatura de Jáuregui:

\begin{tabular}{|c|c|}
\hline \multicolumn{2}{|l|}{ Jáuregui (1850) } \\
\hline zientziac eta ofizizuac & ciencias y artes \\
\hline Zientzia & La ciencia \\
\hline Ofizio bat & Un arte \\
\hline Ofizio liberalac & Las artes liberales \\
\hline Ofizio mekanikakuac & El arte mecánico \\
\hline Gramera & La gramática \\
\hline Errotorika $(1)^{26}$ & La retórica \\
\hline Teologia $(2)^{27}$ & La teología \\
\hline Filozofia & La filosofía \\
\hline Fisika & La física \\
\hline$[\ldots]$ & [...] \\
\hline Yurizprudentzia (3) ${ }^{28}$ & La jurisprudencia \\
\hline Kampainaz eta laborari lanez & del campo y agricultura \\
\hline Herri bat & Un pueblo \\
\hline Herri thiki bat & Una aldea \\
\hline Mendi bat & Una montaña \\
\hline$[\ldots]$ & {$[\ldots]$} \\
\hline Zilo bat & Un foso \\
\hline Haria edo salbia (1) ${ }^{29}$ & Arena \\
\hline Harria & Piedra \\
\hline Kisua & Cal \\
\hline Zorrotz harria & Piedra de amolar \\
\hline Teila bat & Una teja \\
\hline Adrilua edo adealhua (2) ${ }^{30}$ & Ladrillo \\
\hline Arduas bat & Una pizarra \\
\hline Lohia $(3)^{31}$ basa & Barro \\
\hline
\end{tabular}

Jáuregui también explica algunas de las diferencias entre las dos lenguas. Así, en el apartado dedicado a los adjetivos incluye una nota en la que explica las terminaciones de acuerdo al género gramatical: "o ekin akabatzen direnac erraiten dire grizonari eta bestiac emaztekiari; eskuaraz guzieri igual $^{32}$.-En Vascongado todos los nombres singulares se acaban con a, sea masculino o femenino" (Jáuregui 1850, 30).
26 En nota a pie: "Erretorika ongu mintzatzen ikastekomanera" [la retórica es la manera de aprender a hablar bien].

27 En nota a pie: “Teologia erreligioniaren printzipuen yakintasuna" [la teología es el conocimiento de los principios de la religión].

28 En nota a pie: "Yurizprudentzia da leguetan okupatzia" [la jurisprudencia es la dedicación a las leyes].

29 En nota a pie: "Salbia Bache nabartarrez" [salbia en bajonavarro].

30 En nota a pie: "Adealhua id. id.".

31 En nota a pie: "Lohia Bache nabartarrez".

32 Los que terminan en o se utilizan con los hombres y el resto con las mujeres; en euskera a todos con la misma forma [la traducción es mía]. 
3.2.4. Laugarren kapitulua (Cuarto capítulo). "Frases familiares para la conversación, para pedir, preguntar, dar gracias, afirmar, negar $\varepsilon . "$

El último capítulo de la gramática de Jáuregui incluye a unas frases familiares en vasco y castellano. Nuevamente, esta sección se basa en el contenido del Arte de Chantreau: como en los apartados anteriores, el autor únicamente se dedica a cambiar el francés por el euskera, a alterar el orden de las lenguas y a resumir el contenido. Este hecho se advierte de forma clara en los siguientes fragmentos de las obras de Chantreau y de Jáuregui, respectivamente:

\begin{tabular}{|c|c|}
\hline \multicolumn{2}{|l|}{ Chantreau $(1781,91)$} \\
\hline $\begin{array}{l}\text { Yo te romperé la cabeza. } \\
\text { Eres un pícaro. } \\
\text { Si agarro un palo, me las pagarás. } \\
\text { No habrías de tener vergüenza? } \\
\text { Metase Vmd. en lo que le toca. } \\
\text { Déxenos Vmd. en paz. } \\
\text { Sois un majadero. } \\
\text { Mire Vmd. el tonto. } \\
\text { No hay forma de aguantarte. } \\
\text { Esperen, esperen, pícaros, que voy allá a } \\
\text { ponerlos en paz. }\end{array}$ & $\begin{array}{l}\text { Je te casserai la tête. } \\
\text { Tu es un coquin. } \\
\text { Si je prends un bâton, tu me la paieras. } \\
\text { Ne devrois-tu pas avoir honté ? } \\
\text { Mêlez-vous de vos affaires, de ce qui vous } \\
\text { regarde. } \\
\text { Laissez-nous tranquiles. } \\
\text { Vos êtes un butor, un lourdant. } \\
\text { Voyez un peu le sot, l'imbecile. } \\
\text { Il n'y a pas moyen de te souffrir. } \\
\text { Attendez, attendez, M.rs les drôles, je vais } \\
\text { aller mettre le hola entre vous. }\end{array}$ \\
\hline \multicolumn{2}{|l|}{ Jáuregui $(1850,113)$} \\
\hline $\begin{array}{l}\text { Burua hautsiko haut } \\
\text { Kokin bat haiz } \\
\text { Makil bat hartzen badut, doluturen zauc } \\
\text { Ehuke ahalke izan behar? } \\
\text { Zu mela zaite zeure aferez } \\
\text { Trankil utz gaitzatzu } \\
\text { Fastika garri haiz } \\
\text { Beguirazu asto horri } \\
\text { Intsoportable garria haiz } \\
\text { Zaote, zaote, nic bakian ezarriko zaituz tet }\end{array}$ & $\begin{array}{l}\text { Yo te romperé la cabeza } \\
\text { Eres un pícaro } \\
\text { Si agarro un palo, me las pagarás } \\
\text { No habrás de tener vergüenza? } \\
\text { Métase Vd. en lo que le toca } \\
\text { Dejenos Bd. En paz } \\
\text { Es Vd. un majadero } \\
\text { Mire Vd. ese tonto } \\
\text { No hay forma de aguantarte } \\
\text { Esperen, esperen que voy allá a ponerlos en } \\
\text { paz }\end{array}$ \\
\hline
\end{tabular}

Las frases que se insertan en la Gramera berria están divididas en diversos epígrafes, que recogemos la tabla siguiente:

\begin{tabular}{|l|}
\hline Epígrafes \\
\hline [Para pedir, preguntar, dar gracias, afirmar, negar, \&c. $]^{33}$ \\
\hline Para dar los buenos días \\
\hline De la despedida \\
\hline Del ir y venir \\
\hline Del levantarse \\
\hline Para saber, conocer, oír, escuchar \\
\hline Del comer y beber \\
\hline Del paseo \\
\hline Del tiempo \\
\hline De la hora \\
\hline Para enviar una carta \\
\hline
\end{tabular}

Como en la nomenclatura, hemos incluido el epígrafe de Chantreau en los casos en que no está presente en la obra de Jáuregui. 


\begin{tabular}{|l|}
\hline Epígrafes \\
\hline Para hacer un cambio \\
\hline Del juego en general \&c. \\
\hline De la comedia \\
\hline Para hablar con un sastre \\
\hline Con el zapatero \\
\hline Al peluquero \\
\hline Al médico y cirujano \\
\hline Del viage \\
\hline Para desear bien \\
\hline Enojo y enfado \\
\hline Varias cosas que pueden ofrecerse en una tertulia \\
\hline Proverbios y sentencias \\
\hline
\end{tabular}

Tabla 5: Epígrafes del apartado de frases familiares.

Los epígrafes que nos encontramos en la obra de Jáuregui, muy similares a los del Arte de Chantreau ${ }^{34}$, coinciden con los habituales en la enseñanza de segundas lenguas y tienen un carácter funcional y social. Son, por lo tanto, semejantes a los temas que se desarrollan dentro de la tradición de diálogos bilingües o multilingües para la enseñanza y aprendizaje de lenguas extranjeras (Sáez Rivera 2008, 1173-1212). En general, la necesidad de aprendizaje de un idioma obedece a razones de tipo mercantil, político, de viajes o traslados o de predominio de una lengua; en consecuencia, en este tipo de obras hallaremos habitualmente frases usuales que pueden ser utilizadas en diversas situaciones sociales, en la vida cotidiana, en transacciones, etc.

Al final de este apartado, Jáuregui también incluye una sección dedicada a recoger proverbios y sentencias que, de nuevo, es el resumen del capítulo incluido en el "Suplemento" del Arte de Chantreau. Este tipo de unidades fraseológicas aparecen frecuentemente en los manuales de enseñanza de segundas lenguas, incluidos en apartados autónomos en forma de colecciones de refranes - 0 , en ocasiones, constituyendo incluso una obra independiente- o insertos en otros géneros discursivos mayores como, por ejemplo, los diálogos ${ }^{35}$. Se introducen con denominaciones como proverbios, refranes, sentencias o adagia, entre otros (Sáez Rivera 2008, 1245-1248).

\section{Conclusiones}

La Gramera berria de Francisco Jáuregui es un texto bilingüe, en el que se presentan las dos lenguas - esto es, el castellano y el euskera- de forma contrastiva $^{36}$ y en el que apenas encontramos explicaciones e indicaciones gramaticales extensas. Como se ha podido observar, el manual de Jáuregui presenta un contenido muy similar a los materiales para la enseñanza de segundas lenguas: consta de unas nociones de pronunciación, unas tablas de conjugación verbal, un repertorio temático y unas frases usuales. Además, la influencia del Arte de hablar bien francés de Pierre-Nicolas
34 Jáuregui no incluye el apartado "Para dar lección y hablar francés" ni “Juego de billar, y trucos", que sí encontramos en la obra de Chantreau.
36 A este respecto, en su estudio sobre los materiales para la enseñanza del español en los siglos XVII y XVIII, Sáez Rivera señala que, si no se encuentran insertos dentro de un género discursivo mayor, "lo normal es que los refranes se recojan para su memorización en forma de repertorios lexicográficos, ordenados alfabéticamente y lematizados por la primera palabra del refrán" (Sáez Rivera 2008, 250).
36 El método contrastivo es muy frecuente en la historia de la enseñanza de segundas lenguas y es un recurso eficaz, puesto que "al hacer notar al alumno tanto las semejanzas como las diferencias especialmente estas últimas entre las dos lenguas, el aprendizaje se convierte en significativo y facilita que las peculiaridades de la lengua que se está aprendiendo se fijen en la memoria y se vayan consolidando" (Marcos Sánchez 2011, 904) 
Chantreau -o de alguna de sus numerosas reelaboraciones decimonónicas- en la confección del manual es muy evidente, especialmente en el repertorio léxico y en el apartado que contiene una serie de frases usuales y refranes en los dos idiomas.

El texto de Jáuregui no constituye, por tanto, una innovación dentro de la tradición de la enseñanza de lenguas, pero su interés radica en la presencia de la lengua vasca junto con la castellana y, sobre todo, en ser la primera obra en vasco publicada en Argentina, según lo que sabemos hasta ahora. Es relevante asimismo el hecho de que fuera publicada nuevamente en dos ocasiones, en 1860 y 1883, prueba de que el manual del labortano hubo de tener cierto éxito en la ciudad porteña.

A este respecto, creemos que el estudio pormenorizado de estas obras y de los factores externos concernientes a su elaboración puede ayudar a conocer mejor la realidad lingüística de los emigrantes vascos en Argentina, tanto los provenientes de la parte francesa como los de la peninsular ${ }^{37}$. Este es un asunto que ha originado ciertas controversias dentro de los estudios de la emigración vasca en Argentina, sobre todo desde el ámbito historiográfico (entre otros, Álvarez Gila 2010 o Irianni 2010), y que no ha sido investigado de forma pormenorizada desde el área lingüística. Así, si atendemos a las tres ediciones de la obra, cabría preguntarse las razones de su éxito dentro de la comunidad vasca argentina -y especialmente, en los emigrantes procedentes del País Vasco francés, que serían, a priori, los receptores de este manual-. Por otro lado, sería relevante examinar si el manual de Jáuregui habría sido utilizado también para la enseñanza del euskera $^{38}$, especialmente a finales del siglo XIX y principios del XX, en relación con el desarrollo de diversos movimientos de fomento de la cultura y de la lengua vascas (Gómez López 2014). En este sentido, esperamos que la progresiva institucionalización de los estudios vascos en Argentina que se está llevando a cabo en los últimos años ayude al progreso y la ampliación del conocimiento sobre las particularidades del fenómeno de la emigración vasca, así como las características lingüísticas y sociolingüísticas de la comunidad vasca en dicho país.

\section{Reconocimiento}

Este estudio se enmarca dentro de los trabajos de investigación del proyecto Biblioteca Virtual de la Filología Española. Fase III: nuevas bibliotecas y nuevos registros. Información bibliográfica. Difusión de resultados (FFI2017-82437-P) y del proyecto Bibliografía Temática de Historiografía Lingüística Española - Apéndice 1 (FFI2017-85401-P).
37 En relación con esta obra, consideramos de gran interés la reciente noticia acerca de la elaboración de una nueva edición del manual de Jáuregui, que están llevando a cabo diversos investigadores: http://www.euskalkultura. com/espanol/noticias/la-editorialvasco-uruguaya-euskal-erria-reeditaragramera-berria-186o-manual-paraensenar-espanol-a-los-vascos.

38 Sabemos que materiales similares elaborados en el País Vasco se presentaban igualmente para el afianzamiento y fijación (y en algunas ocasiones para el aprendizaje) de la lengua vasca (Fernández de Gobeo 2017, 326-328). 


\section{Q Bibliografía}

》Alvar Ezquerra, Manuel. 2013. Las nomenclaturas del español: Siglos XV-XIX. Madrid: Liceus.

" Álvarez Gila, Óscar. 2002. "Catálogo de los vascos en el censo de Buenos Aires de 1855: las parroquias de Catedral al Norte y San Miguel”. Vasconia 32: 459-490.

" Álvarez Gila, Óscar. 2009. "Euskal hezkuntza ikastolak sortu baino lehen: Amerikako euskal ikastetxeak, egitasmoen eta errealitatearen artean (XVIII-XX)". Uztaro 69: 5-22.

»Álvarez Gila, Óscar. 2010. “¿Vascos o euskaldunak?: una aproximación al papel del euskara en la conformación de las colectividades vascas de América, siglo XIX". Sancho el Sabio 32: 71-84.

" Auza, Gonzalo Javier. 2003. "Apuntes sobre la producción editorial en euskera en Argentina en los siglos XIX y XX, con dos aportes bibliográficos”. Euskonews \& Media 234. Fecha de consulta: 22 de marzo de 2018, <http://www.euskonews.com/o234zbk/kosmo23401.html>.

" Auza, Gonzalo Javier. 2013. "Bibliografía vasca de Argentina 1850-2007". Vasconia 39: 27-100.

" Aramburu, Enrique. 1999. “Noticia sobre una gramática vasca para aprender el castellano en la Biblioteca Nacional del Uruguay”. Euskaldunak - Los vascos 14: 48-50.

" Aramburu, Enrique. 2001. La lengua más antigua de Europa: el vasco en su literatura y apellidos. Buenos Aires: Biblos.

»Esparza Torres, Miguel Ángel y Hans-Josef Niederehe. 2012. Bibliografía cronológica de la lingüística, la gramática y la lexicografía del español (BICRES IV): Desde el año 1801 hasta el año 1860. Ámsterdam: John Benjamins Publishing Company.

"Esparza Torres, Miguel Ángel y Hans-Josef Niederehe. 2015. Bibliografía cronológica de la lingüística, la gramática y la lexicografía del español (BICRES V): Desde el año 1861 hasta el año 1889. Ámsterdam: John Benjamins Publishing Company.

》Fernández de Gobeo, Nerea. 2017. “Materiales bilingües para la enseñanza del castellano en el País Vasco en el siglo XIX”. Tesis de doctorado, Universidad Complutense de Madrid.

" García Aranda, M. Ángeles. 2011a. "La influencia del Arte de hablar bien francés de P. N. Chantreau (1781) en la lexicografía vasca decimonónica”. En La producción lexicográfica: investigación y análisis, coordinado por M. Concepción Ayala Castro, 81-105. Málaga: Servicio de Publicaciones de la Universidad de Málaga.

" García Aranda, M. a Ángeles. 2011b. "La evolución de la lexicografía vasco-románica: las obras de Astigarraga, Jáuregui, Eguren y Juvenal Martyr”. Oihenart 26: 197-215.

» Gómez López, Ricardo. 2014. "La enseñanza del euskera en Argentina durante el "Renacimiento Vasco": el Curso primero del idioma basko en dialecto guipuzkuano (1912) de Soloeta-Dima". RAHL 6.1: 25-49.

" Goizueta, José María de. 1859. “Antiguos cantos vascongados”. La América: crónica hispano-americana, año III, 24 de junio de 1859, 11-12. Disponible en la Hemeroteca Digital de la Biblioteca Nacional de España.Fecha de consulta: 27 de marzo de 2018, <http:// hemerotecadigital.bne.es/issue.vm?id=0002228233\&search=\&lang=es $>$.

"Irianni, Marcelino. 2010. Historia de los vascos en la Argentina. Buenos Aires: Biblos.

" Jáuregui de San Juan, Francisco [François Jauréguy]. 185o. Gramera berria ikasteko eskualdunec mintzatzen espainoles, dibiditua bi partetan; lehena ortografiaren gainian, eta 
bigarrena lenguayaren ikasteko erreski mintzatzen [Nueva gramática, para que los vascos aprendan a hablar en español, dividida en dos partes; la primera sobre la ortografía y la segunda para aprender la lengua fácilmente]. Buenos Aires: Imprenta Republicana.

» Jáuregui de San Juan, Francisco [François Jauréguy]. 1860. Gramera berria ikasteko eskualdunec mintzatzen espainoles; o sea Nueva gramática para enseñar a los vascos a hablar español. Buenos Aires: Librería de Pablo Morta.

» Jáuregui de San Juan, Francisco [François Jauréguy]. 1883. Gramera berria ikasteko eskualdunec mintzatzen espainoles; o sea Nueva gramática para enseñar a los vascos a hablar español. Buenos Aires: Igón Hermanos.

"Larsen, Mariano. 1860. "Introducción" a Gramera berria ikasteko eskualdunec mintzatzen espainoles, de Francisco Jáuregui de San Juan, III-XVI. Buenos Aires: Librería de Pablo Morta.

" Madariaga Orbea, Juan. 2008. Apologistas y detractores de la lengua vasca. San Sebastián: Fundación para el Estudio del Derecho Histórico y Autonómico de Vasconia.

" Marcos Sánchez, Mercedes. 2011. “Orientaciones en la enseñanza del español como lengua extranjera en la Europa del siglo XVIII". En El castellano y su codificación gramatical; Volumen III: De 1700 a 1835, dirigido por José J. Gómez Asencio, 885-920. Burgos: Fundación Instituto Castellano y Leonés de la Lengua.

»Quijada Van den Berghe, Carmen. 2015. "La enseñanza del castellano como L2 a vascoparlantes en el siglo XIX". ReCHERches 14: 175-94.

"Real Academia Española. 1796. Gramática de la lengua castellana. Madrid: viuda de don Joaquín Ibarra.

»Sáez Rivera, Daniel M. 2008. “La lengua de las gramáticas y métodos de español como lengua extranjera en Europa (1640-1726)". Tesis de doctorado, Universidad Complutense de Madrid. 